\title{
MULTIPLIER EFFECTPERTANIAN NANAS (Ananas Comosus) TERHADAP PENYERAPAN TENAGA KERJA DAN PENDAPATANMASYARAKAT DI DESA KUALU NANAS, KECAMATAN TAMBANG, KABUPATEN KAMPAR, PROVINSI RIAU
}

\author{
Ridho Al Magribi ${ }^{1}$, Yurni Suasti ${ }^{2}$, Ratna Wilis ${ }^{2}$ \\ Program Studi Pendidikan Geografi, \\ Fakultas Ilmu Sosial, Universitas Negeri Padang \\ Email: : magribi04@gmail.com \\ Abstrak
}

Tujuan dari penelitian ini adalah untuk mengetahui Multiplier Effect pertanian nanas di Desa Kualu Nanas terhadap penyerapan tenaga kerja dan pendapatan masyarakat. Penelitian ini dilakukan di Desa Kualu Nanas Kecamatan Tambang Kabupaten Kampa Provinsi Riau, Jenis penelitian ini yakni deskriptif kuantitatif. Populasi dan sampel penelitian ini adalah petani buah nanas yang ada di Desa Kualu Nanas Kecamatan Tambang Kabupaten Kampar Provinsi Riau, dengan jumlah 4 sampel dengan melihat sampai pada penjual dan industri dengan menggunakan metode persentase dan mengunakan rumus untuk mengukur multiplier effect.

Penelitian ini menemukan:(1) Multiplier Effectpertanian nanas terhadap penyerapan tenaga kerja berdampak terhadap sektor jasa, industri dan pedagang buah nanas, nilai dari Multiplier Effect adalah 1,195. Nilai ini menunjukan setiap penambahan satu satuan tenaga kerja sektor basis (pertanian nanas) maka akan mengakibatkan penambahan lapangan kerja sektor non basis sebanyak 0,195 kali. Jika pertambahan tenaga kerja sebanyak 10 orang di sektor pertanian nanas (basis) maka akan menciptakan terbukanya lapangan kerja sebanyak 2 orang di sektor non basis. (2) Multiplier Effectpertanian nanas terhadap pendapatan berdampak pada industri dan perdagangan buah nanas dengan angkanya sebesar 3,04. Ini menunjukan bahwa setiap kenaikan satu satuan sektor pertanian nanas (basis) akan mengakibatkan kenaikan sektor non basis sebesar 2,04 kali. Jika pertambahan pendapatan sebanyak Rp.1000.Pada sektor basis maka akan meningkatkan pendapatan sebesar Rp.2.040.Pada sektor non basis. Dari hasil diatas dengan adanya pertanian nanas maka akan menimbulkan Value added atau nilai tambah untuk sektor lainnya.

Kata Kunci : Multiplier Effect Pertanian Nanas.

Kata Kunci: Persepsi, Mata Pelajaran Geografi, Orang Tua Siswa

\section{ABSTRACT}

The purpose of this research is to know the Multiplier Effect of pineapple agriculture in Kualu Nanas village towards the absorption of manpower and community income.This research was conducted in the village of Kualu Nanas, Tambang Subdistrict, Kampa Regency, Riau Province. This research is descriptive quantitative. The population and sample of this research are pineapple farmer in Kampung Riau Village, with 4 sample by looking at seller and industry by using percentage method and using formula to measure multiplier effect.

This research found: (1) Multiplier Effect of pineapple agriculture on the absorption of labor affecting service sector, industry and pineapple trader, the value of Multiplier Effect is 1,195. This value shows every addition of one unit of labor base sector (pineapple agriculture) it will result in the addition of non-base sector employment

\footnotetext{
${ }^{1}$ Mahasiswa Program Studi Pendidikan Geografi untuk Wisuda September 2017

${ }^{2}$ Dosen Jurusan Geografi Fakultas Ilmu Sosial Universitas Negeri Padang
} 
as much as 0.195 times. If the increase of manpower as many as 10 people in the pineapple agriculture sector (base) it will create the opening of employment as much as 2 people in the non-base sector. (2) Multiplier Effect of pineapple agriculture on revenues affects the pineapple industry and trade with a grade of 3.04. This shows that every increase of one unit of pineapple agriculture sector (base) will result in an increase in non-base sector by 2.04 times. If the income increase is Rp.1000. In the base sector it will increase the revenue of $R p$. 2.040. In the non-base sector. From the above results with the existence of pineapple agriculture will cause Value added or added value for other sectors.

Keywords:Multiplier Effect of PineappleFarming

\section{PENDAHULUAN}

Indonesia dikenal sebagai negara agraris yang berarti adalah negara yang mengandalkan sektor pertanian.Yang mengandalkan sektor pertanian baik sebagai mata pencaharianmaupun sebagai penopang pembangunan (Kuncoro, 2010). Indonesia dikenal sebagai negara agraris yang berarti adalah negara yang mengandalkan sektor pertanian.

Karakteristik Indonesia sebagai Negara agraris menyiratkan bahwa sektor pertanian memegang peranan penting di Negara ini.sebutan sebagai Negara agraris bukan tanpa alasan. Negara Indonesia yang merupakan Negara kepulauan dihuni oleh penduduk yang mayoritas tinggal di pedesaan dan mengantungkan hidupnya pada sektor primer khususnya pertanian.

Secara tradisional peranan pertanian dalam pembangunan ekonomi hanya dipandang pasif dan sebagai unsur penunjang semata (Todaro dan Smith, 2006). Sektor pertanian dimasa yang akan datang harus dipandang sebagai suatu sektor ekonomi yang sejajar dengan sektor ekonomi lainnya. Sektor ini harus sejajar dengan sektor industri oleh sebab itu pertanian harus menjadi sektor yang modern, efisien dan berdaya saing.

Sektor pertanian dalam tatanan nasional memegang peranan penting, karena selain bertugas menyediakan pangan bagi seluruh penduduk juga merupakan sektor andalan dalam penyumbangan devisa Negara dari sektor non migas. Besarnya kesempatan kerja yang diserap dan besarnya jumlah penduduk yang bergantung pada sektor ini memberikan arti di masa mendatang, sehingga sektor pertanian ini perlu ditumbuh kembangkan. Hal tersebut menjadikan sektor pertanian merupakan salah satu titik berat pembangunan Indonesia yang menjadi prioritas utama, karena sebagian besar mata pencaharian penduduk Indonesia masih bergerak pada sektor pertanian. Pembangunan di sektor pertanian ini disamping bertujuan untuk meningkatkan pendapatan dan kesejahteraan petani, juga untuk memperluas penganekaragaman hasil pertanian, meningkatkan produksi dalam negeri yang bertujuan ekspor.

Sasaran pembangunan pertanian sekarang tidak hanya fokuskan pada peningkatan produksi, namun juga mengarah pada pendapatan masyarakat, perluasan lapangan kerja, peningkatan taraf hidup petani dan 
perluasan pasar produk pertanian, baik didalam maupun diluar negeri. Salah satu faktor penting dalam pengembangan hasil- hasil pertanian, khususnya bersumber dari hasil perkebunan (Tukan, 2001 dalam Sobirin, 2009: 1).

Nanas (Ananas comosus). Merupakan komoditas andalan dalam perdangangan buah tropik yang menempati urutan ke dua terbesar setelah pisang. Indonesia termasuk produsen terbesar ke lima setelah Brazil, Thailand, Filipina dan Cina (Manuwoto et al., 2003). Di Indonesia terdapat suatu daerah yaitu Desa Kualu Nanas, Riau yang banyak memproduksi nanas dan menjadikan nenas sebagai produk uggulan.

Desa Kualu Nanas banyak yang bekerja sebagai petani yang merupakan subsektor yang menjadi prioritas utama dalam mengembangkan dan meningkatkan kesejahteraan ekonomi para petani. Sebagian besar lahan pertanian dimanfaatkan masyarakat untuk penanaman beberapa komoditas, khususnya komoditas holtikultura nanas.Dengan adanya kegiatan penanaman komoditas holtikultura nanas, mengakibatkan produksi yang bisa didapat dalam sekali panen desa Kualu nanas bisa memproduksi 1.456 ton atau 121 ton per bulan.

Dengan melihat produksi nanas pertahun maka dapat dikatakan nanas sebagai komoditas unggulan dan perlu ada perhatian khusus dalam proses awal dari petani sampai produk ini dimanfaatkan oleh konsumen. Agar nanas yang sudah dipanen tidak rusak sebelum sampai ke konsumen, perlu adanya kegiatan yang cepat dan tepat agar nanas yang sudah dipanen tidak rusak sebelum sampai ke konsumen, dan itu memerlukan kegiatan distribusi yang tepat dan efisien.

Ini juga berpengaruh terhadap sektor lain, misalnya industri yang bahan baku berasal dari buah nanas. Industri memerlukan tenaga kerja, ini mengisyaratkan ada multiplier effect dari kegiatan pertanian nenas sebagai produk unggulan ini.

Seiring dengan berjalannya waktu kegiatan pertanian nanas terutama petani sering mendapatkan kendala baik itu dalam mendapatkan modal bibit dan pemasaran yang berdampak pada kegiatan pertanian nanas itu sendiri. Selain itu pertanian nanas di desa Kualu Nanas ini juga mendukung sektor pariwisata sebagai komoditas khas desa Kualu Nanas.

Dalam pengembangan sektor pertanian nanas, sangat diharapkan dapat menjadi perhatian pemerintah dan pelaku ekonomi lainnya, agar kegiatan ini dapat berkembang dengan baik. Berdasarkan latar belakang masalah di atas, maka penulis tertarik untuk melakukan penelitian yang berjudul “Multiplier Effect Pertanian Nenas (Ananascomosus) Terhadap Penyerapan Tenaga Kerja Dan Pendapatan Masyarakat Di Desa Kualu Nanas, Kecamatan Tambang Kabupaten Kampar, Provinsi Riau".

Penelitian ini bertujuan untuk mengetahui sejauh mana Multiplier effect pertanian nanas terhadap tenaga kerja yang terserap. dan sejauh mana Multiplier Effect pertanian nanas terhadap pendapatan masyarakat di daerah penelitian.

\section{METODE PENELITIAN}

Jenis penelitian adalah penelitian deskriptif pendekatan kuantitatif. Populasi penelitian petani nanas di Desa Kualu Nanas sebanyak 102 orang yang tergabung dalam Gapoktan (Gabungan Kelompok Tani). Pengambilan sampel dilakukan secara Teknik Random Sampling 
dengan mengambil 4 dari petani secara acak dan juga melihat rantai distribusi hasil buah nanas nya hingga ke industri olahan buah nanas dan penjual buah nanas. Teknik pengumpulan data menggunakan wawancara. Di analisis menggunakan formulasi presentase. Menghitung perentase $(\%)$ dengan menggunakan formula.

Dimana :

$$
\mathrm{P}=\frac{f}{n} \times 100 \%
$$

$\mathrm{P}=$ Persentase

$\mathrm{f} \quad=$ Frekuensi jawaban

$\mathrm{n} \quad$ =Jumlah seluruh responden untuk mengetahui nilai dari

Multiplier Effect terhadap penyerapan tenaga kerja di daerah penelitian dengan menggunakan formula

$\mathrm{ME}=\mathrm{TK}$ Basis + TK Non Basis /TK Basis

dimana

$$
\begin{aligned}
& \text { ME } \quad=\text { Multiplier Effect } \\
& \text { TK Basis } \quad=\text { Tenaga Kerja Sektor } \\
& \text { Unggulan } \\
& \text { TK Non Basis = Tenaga Kerja sektor } \\
& \text { Non unggulan }
\end{aligned}
$$

\section{HASIL DAN PEMBAHASAN}

Berdasarkan temuan penelitian yang telah dilakukan dengan wawancara dengan responden maka Multiplier Effect terhadap Penyerapan Tenaga Kerja dan Pendapatan masyarakatDalam suatu kegiatan pertanian nanas pasti berdampak pada sektor lain misalnya jasa, perdagangan dan industri.

\section{Multiplier Effect Pertanian Nanas Terhadap Penyerapan Tenaga Kerja.}

Sebagaimana hasil penelitian yang telah dilakukan mengenai Multiplier effect pertanian nanas terhadap penyerapan Tenaga Kerja dan Pendapatan Masyarakat di Desa Kualu Nanas, Kecamatan Tambang, Kabupaten Kampar, Provinsi Riau terlihat petani nanas masih termasuk pada petani sederhana dan industri olahan buah nanas di Desa Kualu Nanas masih tergolong industri rumah tangga ini dapat dilihat dari jumlah tenaga kerja yang ada dan kegiatan industri olahan buah nanas ini masih dianggap sebagai mata pencaharian tambahan.

Kegiataan Pertanian buah nanas adalah kegiatan utama warga desa Kualu Nanas, dengan adanya kegiatan pertanian buah nanas ini maka buah nanas menjadi komoditas unggulan di Desa Kualu Nanas, dan beberapa dari masyarakat membuka industri olahan buah nanas dan ini bisa menjadi lapangan pekerjaan baru.

Dari 4 responden yang menjadi informan maka total penyerapan tenaga kerja yaitu sebanyak 239 tenaga kerja. Untuk sektor petani terserap tenaga kerja sebanyak 200 tenaga kerja, untuk jasa Terserap 19 tenaga kerja, untuk industri terserap 16 tenaga kerja, dan penjual terserap 4 tenaga

Untuk mengetahui Multiplier Effect dari Tenaga Kerja maka dapat menggunakan rumus sebagai berikut:

$M E=T K$ Sektor basis + TK Sektor Non Basis TK Basis

$\mathrm{ME}=\underline{200+(19+16+4)}$

200

$\mathrm{ME}=1,195$

Dari perhitungan diatas maka dapat diketahui nilai Multiplier Effect terhadap tenaga kerja adalah 1,195 .

Dari hasil diatas maka dapat diinterpretasikan bahwa dengan adanya sektor basis yaitu pertanian buah nanas mampu meningkatkan penyerapan tenaga kerja pada sektor basis itu maupun pada sektor non basis seperti jasa, industri dan penjual buah nanas, untuk Multiplier Effect tenaga kerja sebesar 1,195 maka setiap kenaikan satu satuan tenaga kerja sektor basis akan 
mengakibatkan perubahan lapangan tenaga kerja total sebanyak 1,195 kali. Atau dengan artian, pertambahan 1 tenaga kerja sektor pertanian nanas maka akan membuka peluang tenaka kerja sebesar 0,195 pada sektor lanjutan (non basis).

Ini sesuai dengan teori multiplier effect yaitu dampak dari peningkatan yang diakibatkan oleh sektor tertentu maka sektor lain akan terkena dampak nya. Dalam hal ini adalah akibat dari sektor basis (pertanian nanas) mempengaruhi sektor non basis (industri olahan buah nanas, dan penjual buah nanas, dan juga jasa).

\section{Multiplier Effect Pertanian Nanas Terhadap Pendapatan.}

Sebagaimana hasil penelitian yang telah dilakukan mengenai Multiplier effect pertanian nanas terhadap Pendapatan Masyarakat di Desa Kualu Nanas, Kecamatan Tambang.Berdasarkan penelitian yang dilakukan, maka dapat dilihat untuk semua responden yang diteliti maka Total pendapatan semua nya adalah Rp.147.152.999. untuk sektor petani diperoleh jumlah pendapatan Rp.48.332.999. untuk sektor Industri total pendapatan nya adalah Rp.80.820.000.dan total pendapatan penjual buah nanas pinggir jalan adalah Rp. 18.000.000. dan juga menggerakkan sektor jasa dengan upah rata-rata Rp.100.000 per hari orang kerja.

Untuk mengetahui Multiplier Effect terhadap pendapatan maka dapat menggunakan rumus sebagai berikut:

$M E=$ pendapatan basis + pendapatan Non Basis Pendapatan Basis

$\mathrm{ME}=48.332 .999+(80.820 .000+18.000000)$ 48.332 .999

$\mathrm{ME}=3,04$
Dari perhitungan di atas maka dapat diketahui nilai Multiplier Effect terhadap pendapatan adalah 3,04.

Dari hasil di atas maka dapat diinterpretasikan bahwa dengan adanya sektor basis yaitu pertanian buah nanas mampu meningkatkan pendapatan pada sektor basis itu maupun pada sektor non basis seperti industri dan penjual buah nanas, untuk Multiplier Effect tenaga kerja sebesar 3,04 maka setiap kenaikan satu satuan sektor basis akan mengakibatkan perubahan pendapatan total sebanyak 3,04 kali. Atau dengan kata lain dengan pertambahan pendapatan sebesar Rp. 1000. Pada sektor pertanian nanas (basis) maka akan meningkatkan pendapatan pada sektor lanjutan sebesar Rp.2040.

Ini sesuai dengan teori multiplier effect yaitu dampak dari peningkatan pendapatan yang diakibatkan oleh sektor tertentu maka sektor lain akan terkena dampak nya. Dalam hal ini adalah akibat dari sektor basis (pertanian nanas) mempengaruhi sektor non basis (industri olahan buah nanas, dan penjual buah nanas).

Dari penelitian yang telah dilakukan dapat dirasakan Multiplier Effect dari Pertanian Nanas, yang mana mampu berdampak mengembangkan sektor lain misalnya jasa, perdagangan dan industri ini sangat berpengaruh dalam penyerapan tenaga kerja serta pendapatan masyarakat setempat.

\section{SIMPULAN DAN SARAN}

Berdasarkan hasil penelitian dan pembahasan tentang Multiplier Effect pertanian nanas terhadap penyerapan tenaga kerja dan pendapatan masyarakat di desa Kualu Nanas, Kecamatan Tambang, 
Kabupaten Kampar diperoleh hasil sebagai berikut:

1. Multiplier effect pertanian nanas di Desa Kualu Nanas terhadap Tenaga Kerja.

Dari penelitian yang dilakukan maka dapat dirasakan multiplier effect pertanian nanas terhadap penyerapan tenaga kerja di Desa Kualu Nanas yaitu dari semua responden total tenaga kerja terserap adalah 239 tenaga kerja dengan rincian pada sektor Pertanian terserap tenaga kerja sebanyak $200(83,68 \%)$ tenaga kerja, untuk sektor jasa terserap sebanyak $19(7,95 \%)$ tenaga kerja, pada sektor industri terserap $16(6,7 \%)$ tenaga kerja, dan pada sektor Perdagangan/ penjual pinggir jalan terserap sebanyak $4(1,67 \%)$ tenaga kerja.

Dengan banyaknya tenaga kerja yang terserap dari setiap sektor maka dengan menggunakan rumus tertentu maka didapat hasil atau angka Multiplier Effect terhadap Tenaga Kerja yaitu sebesar 1.33 ini adalah nlai atau angka yang rasional unutk Multiplier Effect.

2. Multiplier effectpertanian nanas di Desa Kualu Nanas terhadap Pendapatan.

Dari penelitian yang dilakukan maka dapat dirasakan multiplier effect pertanian nanas terhadap pendapatan masyarakat di Desa Kualu Nanas yaitu dari semua responden total pendapatannya adalah Rp.147.152.999. dengan rincian pada Sektor Petani total pendapatannya adalah Rp.48.332.999 (32,85\%), pada sektor Industri total pendapatannya adalah Rp.80.820.000 (54,92\%), dan pada sektor perdagangan Rp.18.000.000 (12,23\%).
Maka dengan adanya kegiatan pertanian nanas di Desa Kualu Nanas maka mempunyai Multiplier Effect terhadap pendapatan masyaraakat pada sektor lain yaitu Jasa, industri, dan perdagangan buah nanas pinggir jalan.

Dengan demikian pertanian nanas harus dikembangkan dan dikelola dengan baik agar tetap terjaganya multiplier Effect nya terhadap tenaga kerja dan pendapatan di Desa Kualu Nanas

Berdasarkan hasil pembahasan dalam penelitian ini maka penulis memberikan beberapa saran yang dapat dijadikan bahan pertimbangan dalam upaya mengembangkan potensi ekonomi di Desa Kualu Nanas. Saran dalam penelitian ini sebagai berikut:

1. Dalam segi produksi buah nanas, buah nanas harus diproduksi dengan berkala sehingga bisa memenuhi kebutuhan untuk konsumen dan industri per hari nya dan tidak hanya ada pada musim panen saja.

2. Harus ada pengaturan dari penyuluhan pertanian agar lebih efektif dalam pola tanam agar bisa mencukupi kebutuhan bahan baku per harinya

3. Masyarakat desa Kualu Nanas juga dapat berkerja sama dan membuka industri olahan buah nanas serta mengembangkannya agar penyerapan tenaga kerja dan pendapatan masyarakat bertambah.

\section{DAFTAR PUSTAKA}

Kuncoro, 2010).

Todaro dan Smith, 2006.

Tukan, 2001 dalam Sobirin, 2009: 1

Manuwoto et al., 2003 